\title{
IEEE TRANSACTIONS ON
}

\section{APPLIED}

SUPERCONDUCTIVITY

A PUBLICATION OF THE IEEE COUNCIL ON SUPERCONDUCTIVITY

JUNE 2017

VOLUME 27

NUMBER 4

ITASE9

(ISSN 1051-8223)

PART II OF THREE PARTS

THE 2016 APPLIED SUPERCONDUCTIVITY CONFERENCE

Denver, CO, USA, September 4-9, 2016

\section{LARGE SCALE}

(See first page of Part I for Electronics Table of Contents. Electronics papers begin with Article Number 0100101. See first page of Part II for Large Scale Table of Contents. Large Scale papers begin with Article Number 3500106. See first page of Part III for Materials Table of Contents. Materials papers begin with Article Number 6000105.) 


\title{
IEEE TRANSACTIONS ON APPLIED SUPERCONDUCTIVITY
}

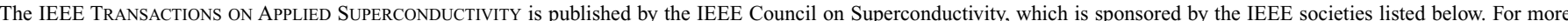

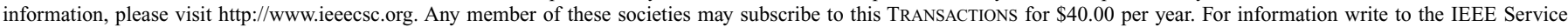
Center at the address below. Member copies of Transactions/Journals are for personal use only.

\author{
Communications \\ H. FreEMAN, President \\ Components, Packaging, and Manufacturing Technology \\ J. TREwhella, President \\ Computer \\ J.-L. GAUDIOT \\ Dielectrics and Electrical Insulation \\ P. LEWIN, President
}

\section{Sponsoring Societies}

Electron Devices
S. SAHA, President
Instrumentation and Measurement
R. DYER, President
Magnetics
B. TERRIS, President

B. TERRIS, President

B. Strauss, President
Council on Superconductivity

L. CoOley, Vice President-Publications

\author{
Microwave Theory and Techniques \\ K. WU, President \\ Power \& Energy \\ D. Novosel, President \\ Reliability \\ C. Hanson, President \\ Ultrasonics, Ferroelectrics, and Frequency Control \\ C. NGuYen, President
}

A. Della Corte, Past President

\section{Editor-in-Chief}

B. L. T. PLOURDE

Syracuse University

bplourde@syr.edu

Editors for Materials

P. J. LEE

Florida State University

lee@asc.magnet.fsu.edu

N. NEWMAN

Arizona State University

Nathan.Newman@asu.edu

M. JEWELL

University of Wisconsin Eau

Claire

jewellmc@uwec.edu

V. SELVAMANICKAM

University of Houston

selva@uh.edu

\begin{tabular}{ll}
\multicolumn{2}{c}{ Editors for Large-Scale Applications } \\
M. PARIZH & M. NOE \\
General Electric & Karlsruhe Institute of Technology \\
parizh@ge.com & mathias.noe@kit.edu \\
S. W. SCHwENTERLY & S. FARINON \\
Oak Ridge National Laboratory & Istituto Nazionale di Fisica Nucleare \\
(Retired) & (INFN) \\
schwenterly@ieee.org & stefania.farinon@ge.infn.it \\
P. J. MASsON & C. LuONGO \\
University of Houston & ITER \\
pjmasson@uh.edu & Cesar.Luongo@iter.org \\
A. DEVRED & A. POLASEK \\
ITER & Electric Power Research Center \\
Arnaud.Devred@iter.org & polasek@cepel.br \\
L.CHIESA & N. AMEMIYA \\
Tufts University & Kyoto University \\
Luisa.Chiesa@tufts.edu & amemiya.naoyuki.6a@kyoto-u.ac.jp
\end{tabular}

\begin{tabular}{|c|c|}
\hline \multicolumn{2}{|c|}{ Editors for Electronic Applications } \\
\hline $\begin{array}{l}\text { A. I. BRAGINSKI } \\
\text { Forschungszentrum Jülich } \\
\text { a.braginski@fz-juelich.de }\end{array}$ & $\begin{array}{l}\text { H. ROGALLA } \\
\text { University of Colorado at Boulder } \\
\text { h.rogalla@ieee.org }\end{array}$ \\
\hline $\begin{array}{l}\text { J. MAZIERSKA } \\
\text { James Cook University } \\
\text { j.mazierska@ieee.org }\end{array}$ & $\begin{array}{l}\text { S. M. ANLAGE } \\
\text { University of Maryland } \\
\text { anlage@umd.edu }\end{array}$ \\
\hline $\begin{array}{l}\text { O. MUKHANOV } \\
\text { Hypres, Inc. } \\
\text { mukhanov@hypres.com }\end{array}$ & $\begin{array}{l}\text { C. A. KILBOURNE } \\
\text { NASA Goddard Space Flight Center } \\
\text { Caroline.A.Kilbourne@nasa.gov }\end{array}$ \\
\hline $\begin{array}{l}\text { A. W. KLEINSASSER } \\
\text { Jet Propulsion Laboratory } \\
\text { alan.w.kleinsasser@jpl.nasa.gov }\end{array}$ & \\
\hline $\begin{array}{l}\text { D. E. OATES } \\
\text { MIT Lincoln Laboratory } \\
\text { oates@11.mit.edu }\end{array}$ & \\
\hline
\end{tabular}

Karen BARTLESON, President JAMES A. JefFERIES, President-Elect WILliam P. WALSH, Secretary JOHN W. WALZ, Treasurer BARRY L. SHOOP, Past President

\author{
IEEE Officers \\ S. K. RAMESH, Vice President, Educational Activities \\ Samir M. El-Ghazaly, Vice President, Publication Services and Products \\ MARY ElLen RANDALl, Vice President, Member and Geographic Activities \\ ForRest D. WRIGHT, President, Standards Association \\ MARINA RUGgIERI, Vice President, Technical Activities \\ KAREN S. Pedersen, President, IEEE-USA \\ Toshio FuKUDA, Director, Division $X$
}

IEEE Executive Staff

DR. E. JAMES PRENDERGAST, Executive Director \& Chief Operating Officer

THOMAS SIEGERT, Business Administration

Julie Eve CozIn, Corporate Governance

DONNA HOURICAN, Corporate Strategy

JAMIE MOESCH, Educational Activities

EILEEN M. LACH, General Counsel \& Chief Compliance Officer

VACANT, Human Resources

Chris BRANTLEY, IEEE-USA

\author{
CHERIF AMIRAT, Information Technology \\ KAREN HAWKINS, Marketing \\ CECELIA JanKowsKi, Member and Geographic Activities \\ MichAEL Forster, Publications \\ KONSTANTINOS KARACHALIOS, Standards Association \\ MARY WARD-CALLAN, Technical Activities
}

IEEE Periodicals

Transactions/Journals Department

Senior Director, Publishing Operations: FRAN ZAPPULLA

Director Editorial Services: DAWN MELLEY Director Production Services. PETER M. TUOHY

Associate Director, Editorial Services: WILliAm A. COLACCHIO Associate Director, Information Conversion and Editorial Support: KeVIN LISANKIE Managing Editor: CHRISTOPHER PERRY Journals Coordinator: SHANNON N. CAMPOS

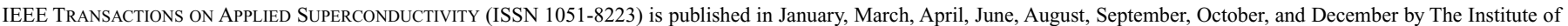

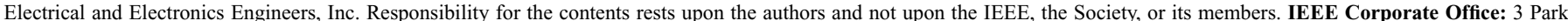

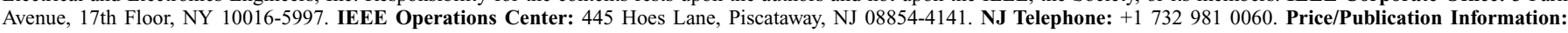

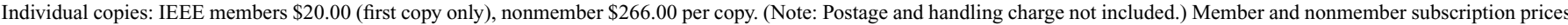

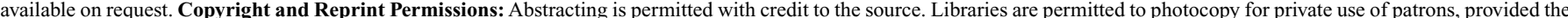

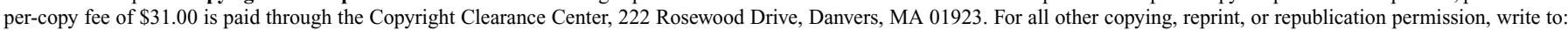

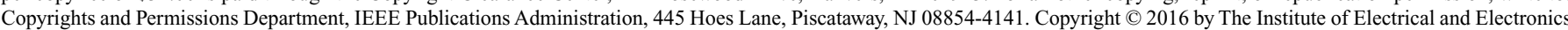

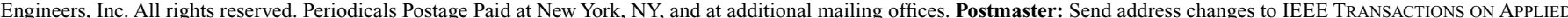

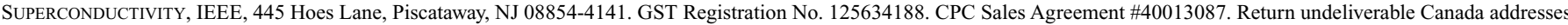

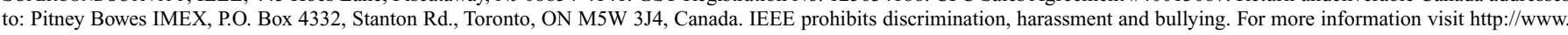
ieee.org/nondiscrimination. Printed in U.S.A. 


\section{IEEE TRANSACTIONS ON}

\section{APPLIED}

\section{SUPERCONDUCTIVITY}

\section{A PUBLICATION OF THE IEEE COUNCIL ON SUPERCONDUCTIVITY}

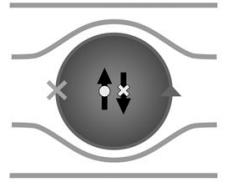

JUNE 2017

VOLUME 27

NUMBER 4

ITASE9

(ISSN 1051-8223)

\section{PART II OF THREE PARTS}

THE 2016 APPLIED SUPERCONDUCTIVITY CONFERENCE

Denver, CO, USA, September 4-9, 2016

\section{LARGE SCALE}

\section{PAPERS}

\section{Superconducting RF}

Impact of Remanent Magnetic Field on the Heat Load of Original CEBAF Cryomodule

. G. Ciovati, G. Cheng, M. Drury, J. Fischer, and R. Geng

Temperature and Microstructural Effects on the Superconducting Properties of Niobium Thin

Films ............................................... R. Beebe, A.-M. Valente-Feliciano,

D. B. Beringer, J. A. Creeden, S. E. Madaras, Z. Li, K. Yang, L. Phillips, C. E. Reece, and R. A. Lukaszew Hybrid Physical Chemical Vapor Deposition of Magnesium Diboride Inside 3.9 GHz Mock Cavities.

.................................... Lee, W. K. Withanage, T. Tan, M. A. Wolak, A. Nassiri, and X. Xi

Levitation, Transportation, and Propulsion

Experimental Production of a Real-Scale REBCO Magnet Aimed at Its Application to Maglev

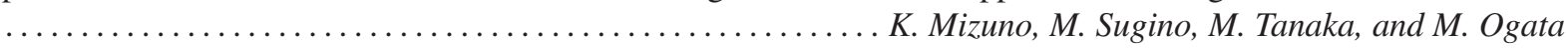
HTS System and Component Targets for a Distributed Aircraft Propulsion System (Invited Paper) ..............

F. Berg, J. Palmer, P. Miller, and G. Dodds Levitation Performance of YBCO Bulks in Supercooling Condition Under a Low-Pressure Environment ... 


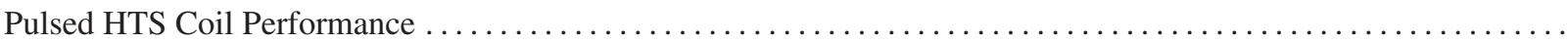

O. Christianson, M. Mielnik, D. Hackworth, J. Pfotenhauer, F. Miller, E. Sheehan, and T. Hordubay

Observation and Analysis of Defects in Impregnated YBCO Racetrack Coil

S. Chen, C. Gu, T. Qu, L. Lai, N. Hu, and Y. Jiang

4603104

Current Behavior Simulation in Stacked NI REBCO Pancake Coils During Local Normal-State Transition......... . S. Noguchi, R. Miyao, K. Monma, H. Igarashi, H. Ueda, and A. Ishiyama Heating and Loading Process Improvement for Indium Inserted Mechanical Lap Joint of REBCO Tapes.......... $\ldots \ldots \ldots \ldots \ldots \ldots \ldots \ldots \ldots \ldots \ldots \ldots \ldots \ldots \ldots \ldots \ldots \ldots \ldots \ldots \ldots \ldots \ldots \ldots \ldots \ldots \ldots$. Ito, and H. Hashizume

Feasibility Study of the Impregnation of a No-Insulation HTS Coil Using an Electrically Conductive Epoxy ....... Y. J. Hwang, J. Y. Jang, S. Song, J. M. Kim, and S. Lee

Quench Analysis of a Multiwidth No-Insulation 7-T 78-mm REBCO Magnet...................... K. R. Bhattarai, K. Kim, S. Kim, S. Lee, and S. Hahn

A Conduction-Cooled REBCO Magnet With a Single-Stage GM Cryocooler and a Stainless Steel Case for Storing

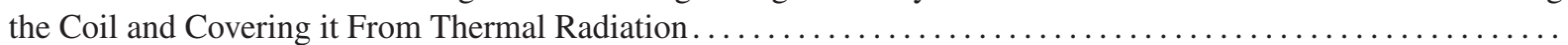
S. Iwai, H. Miyazaki, Y. Otani, T. Tosaka, K. Tasaki, S. Nomura, and Y. Ishii Fast Charging and Thermal Stability Improvement of a Conduction Cooled HTS Coil Wound by Graphene Oxide

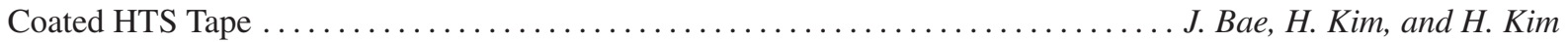

Design and Test Results of a Cryogenic Cooling System for a 25-T Cryogen-Free Superconducting Magnet ............................................... Takahashi, S. Iwai, H. Miyazaki, T. Tosaka, K. Tasaki, S. Hanai, S. Ioka, H. Takigami, K. Watanabe, S. Awaji, H. Oguro, and Y. Tsuchiya

Magnet Stability, Magentization Effects, AC Losses, and Protection

Experiment and Numerical Simulation on Quench Characteristics of ReBCO-Impregnated Coil ... $\ldots \ldots \ldots \ldots \ldots \ldots \ldots \ldots \ldots \ldots \ldots \ldots \ldots \ldots \ldots \ldots \ldots \ldots \ldots \ldots$ Wang, K. Tsuchiya, S. Fujita, S. Muto, and Y. Iijima

Next Generation of Quench Detection Systems for the High-Luminosity Upgrade of the LHC.

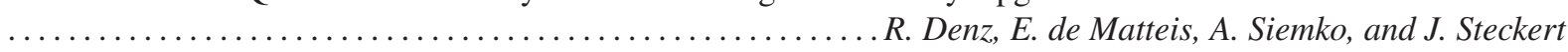

Analysis of Quench Propagation in the ITER Central Solenoid Insert (CSI) Coil ... R. Bonifetto, T. Isono, N. Martovetsky, L. Savoldi, and R. Zanino Overview of the Performance of Quench Heaters for High-Current LHC Superconducting Magnets ............ ....... Z. Charifoulline, L. Bortot, R. Denz, F. R. Mateos, A. Siemko, J. Steckert, A. Verweij, and G. Willering

Eddy-Currents and Force Analysis for the Thermal Shields of the Warm Iron Superconducting Quadrupoles for the FRIB Fragment Separator.......................... S. Chouhan, M. A. Green, and A. F. Zeller

Quench Protection Using CLIQ of $\mathrm{MgB}_{2} 0.5 \mathrm{~T}$ Persistent Mode Magnet.

C. Poole, T. Baig, R. J. Deissler, and M. Martens

Magnetic Shielding Characteristics of Hybrid High-Temperature Superconductor/Ferromagnetic Material Multilayer

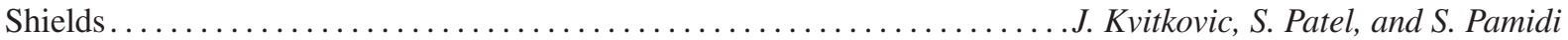

Scribing Effect on Shielding Current in REBCO Superconducting Coils .... M. Iwakuma, K. Nabekura, K. Yun, K. Yoshida, S. Sato, A. Tomioka, M. Konno, A. Ibi, T. Machi, and T. Izumi

Study on Thermal-Quench Behaviors of GdBCO Coils Wound With Silicon Grease as an Insulation Material ...... ............. S.-G. Kim, Y. H. Choi, D. G. Yang, S.-H. Jeong, J. H. Kim, H.-M. Kim, Y. S. Choi, and H. Lee

AC Loss Analysis of a Hybrid HTS Magnet for SMES Based on $H$-Formulation . . . . . . . . . . . . . . . $\ldots \ldots \ldots \ldots \ldots \ldots \ldots \ldots \ldots \ldots \ldots \ldots \ldots \ldots \ldots \ldots \ldots \ldots \ldots \ldots \ldots \ldots$ Z. Wang, Y. Tang, L. Ren, J. Li, Y. Xu, Y. Liao, and X. Deng

Operational Results of a Thermal-Hydraulic Quench Detection System for the KSTAR TF Superconducting Coils ... $\ldots \ldots \ldots \ldots \ldots \ldots \ldots \ldots \ldots \ldots \ldots \ldots \ldots \ldots \ldots \ldots \ldots \ldots \ldots \ldots \ldots$ Y. . Kam, and Y. Chu

Study on Quench Detection of the KSTAR PF Coils Using Numerical Compensation of Inductive Voltages With Genetic Algorithm.......................................... S. C. An, Y. Choi, T. K. Ko, and Y. Chu

Three-Dimensional Numerical Simulation Employing Normal Zone Propagation Velocity on Heat Propagation of ITS Maonet Under Ouench Process I Y Jang $Y$ I Hwang S Lee I Kim S Lee and $M C$ Ahn

4603205

4603305 4603405 4603505 4603605 4603704 4603805 


\section{IEEE Transactions on Applied Superconductivity}

\begin{tabular}{ll|l} 
Popular Early Access & Current Issue Past Issues
\end{tabular}

About Journal

Submit Your Manuscript

About this Journal

Aims \& Scope

\section{Editorial Board}

IEEE Transactions on Applied Superconductivity publication information

\section{Content Announcements}

Become a published author in 4 to 6 weeks

\section{Author Resources}

IEEE Author Digital Toolbox

Additional Information

IEEE Open Access Publishing

Options

\section{Sponsor}

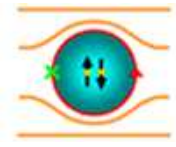

\section{Contacts}

\section{Editor-in-Chief}

Britton L. T. Plourde

Syracuse University

bplourde@syr.edu

http://asfaculty.syr.edu/pages/phy/plourdebritton.html

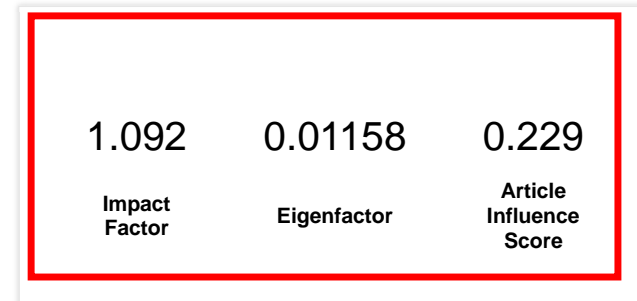

\section{Aims \& Scope}

IEEE Transactions on Applied Superconductivity (TASC) contains articles on the applications of superconductivity and other relevant technology. Electronic applications include analog and digital circuits employing thin films and active devices such as Josephson junctions. Large scale applications include magnets for power applications such as motors and generators, for magnetic resonance, for accelerators, and cable applications such as power transmissions.

Persistent Link: http://ieeexplore.ieee.org/servlet/opac?punumber=77

Frequency: 6

ISSN: $1051-8223$

Published by:

- The IEEE Council on Superconductivity

\section{Subjects}

\section{Contacts}

Engineered Materials, Dielectrics \& Plasmas

Fields, Waves \& Electromagnetics
Editor-in-Chief

Britton L. T. Plourde

Department of Physics

Syracuse University

223 Physics Building

Syracuse, NY 13244 USA

bplourde@syr.edu

http://asfaculty.syr.edu/pages/phy/plourde-britton.html 


\title{
Simulation of Screening Current Reduction Effect in REBCO Coils by External AC Magnetic Field
}

\author{
So Noguchi and Vlatko Cingoski
}

\begin{abstract}
Second-generation
high-temperature superconducting (HTS) tapes have been examined for applications, such as NMR, MRI, and accelerators. Each of these applications requires a precise magnetic field profile. However, screening currents induced while charging an HTS magnet degrade its magnetic field quality. Techniques to reduce the screening current effect have been proposed in the literature. One of the means to reduce screening currents is to apply an AC magnetic field using a "shaking magnet." The shaking effect enhances the quality of magnetic field by reallocating the screening currents inside HTS tapes. Although some experiments to study the shaking field effect were reported, the current distribution inside HTS tapes has not yet been clarified by simulation.

This paper presents the simulation results for an $\mathrm{AC}$ magnetic field applied to a REBCO tape to reduce the influence of screening currents. In addition, we investigated the influence of the angle of applied $\mathrm{AC}$ magnetic field at the magnet center. The area of negative current density is also shown. From the simulation results, we conclude that a shaking field applied at an angle between 10 and $30 \mathrm{deg}$. is effective to reduce the screening current effect.
\end{abstract}

Index Terms-Field homogeneity, REBCO tape, screening current, shaking magnet.

\section{INTRODUCTION}

$\mathrm{S}^{\mathrm{t}}$ ECOND-generation high-temperature superconducting (HTS) tapes are used to develop ultra-high-field NMR and MRI magnets, e.g., 1.3-GHz NMR [1] and 9.4-T MRI [2]. These HTS applications have two critical problems. The first one is a quench protection, and the other is the field inhomogeneity caused by screening currents. For the former, the No-Insulation winding technique is a promising solution [3], [4]. For the latter, a few techniques to reduce the influence of screening current on the field homogeneity were proposed [5], [6], however, these reports are insufficiently conclusive.

The screening currents deteriorate the field homogeneity in the neighborhood of magnet center [7]. In a REBCO tape, a large screening current is induced by the transverse field due to the tape's flat shape. Recently, the screening current effect on the field homogeneity was clarified by simulation [8]. A

This work was supported in part by the JSPS KAKENHI (Grant Number 15KK0192). Corresponding author: So Noguchi.

S. Noguchi is with the Francis Bitter Magnet Laboratory, Plasma Fusion and Science Center, Massachusetts Institute of Technology, Cambridge, MA 02139 , USA as a visiting scientist and with the Graduate School of Information Science and Technology, Sapporo 060-0814, Japan (e-mail: noguchi@ssi.ist.hokudai.ac.jp).

V. Cingoski is with the Faculty of Electrical Engineering, University "Goce Delcev" - Stip, Skopje, 1000, Macedonia. promising screening-field reduction solution is to apply a small AC magnetic field to REBCO tapes using a so-called "shaking magnet" [6], [9].

The screening current phenomena in REBCO tapes were investigated in a number of works [8], [10]-[13], in which the simulation models and results were presented. Also, there exist works where the AC field shaking effect on HTS coated conductors was viewed [14], [15]. However, the current distribution caused by the shaking field inside a REBCO tape has not been simulated so far.

In this paper, we employ a 2D finite element method (FEM) just to model the current distribution inside a REBCO tape affected by an external AC magnetic field applied at different angles to the tape wide surface that, in the end, enabled me to find the most effective angle.

\section{Simulation Method AND Model}

\section{A. Simulation Method}

The governing equation is given by

$\nabla \times(\nu \nabla \times \boldsymbol{A})=\boldsymbol{J}_{0}+\boldsymbol{J}_{\mathrm{S}}$

where $v, \boldsymbol{A}, \boldsymbol{J}_{0}$, and $\boldsymbol{J}_{\mathrm{S}}$ are the magnetic reluctivity, the vector potential, the transport current density, and the screening current density, respectively. Here, the transport and screening current densities are defined as follows:

$\boldsymbol{J}_{0}=-\sigma \frac{\partial \boldsymbol{A}^{\prime}}{\partial t}$
$\boldsymbol{J}_{\mathrm{S}}=-\sigma\left(\frac{\partial \boldsymbol{A}^{\prime \prime}}{\partial t}+\nabla \phi\right)$

where $\boldsymbol{A}^{\prime}+\boldsymbol{A}^{\prime \prime}=\boldsymbol{A}$ and $\phi$ is the scalar potential. Then, $\boldsymbol{J}_{0}+\boldsymbol{J}_{\mathrm{S}}$ is represented by

$\int_{S}\left(\boldsymbol{J}_{0}+\boldsymbol{J}_{\mathrm{S}}\right) \cdot \mathrm{d} \boldsymbol{S}=-\int_{S} \sigma\left(\frac{\partial \boldsymbol{A}}{\partial t}+\nabla \phi\right) \cdot \mathrm{d} \boldsymbol{S}=I_{0}$

where $\sigma, t, I_{0}$, and $\boldsymbol{S}$ are the electrical conductivity, the time, the transport current, and the cross-sectional area of all the conductors, respectively. In the simulation, we assumed that the current passes only in the $z$-direction, and that the gradient of $\phi$ and the electrical conductivity $\sigma$ are constant within a given finite element. From (4), the following equation is derived [16]:

$\frac{\partial \phi}{\partial z}=\left(\int_{S} \sigma \frac{\partial A}{\partial t} \mathrm{~d} S-I_{0}\right) / \int_{S} \sigma \mathrm{d} S$

Substituting (4) and (5) into (1), we obtain the governing equation to be solved using the 2D FEM: 
$v\left(\frac{\partial^{2} A}{\partial x^{2}}+\frac{\partial^{2} A}{\partial y^{2}}\right)=\sigma\left(\frac{\partial A}{\partial t}+\frac{\int_{S} \sigma \frac{\partial A}{\partial t} \mathrm{~d} S-I_{0}}{\int_{S} \sigma \mathrm{d} S}\right)$

Here, the equivalent conductivity of the REBCO layer $\sigma_{\mathrm{S}}$ is assumed to be derived from the $E-J$ power law:

$$
\sigma_{\mathrm{S}}=\frac{|\boldsymbol{J}|}{E_{\mathrm{C}}}\left(\frac{J_{\mathrm{C}}}{|\boldsymbol{J}|}\right)^{n}
$$

where $J_{\mathrm{C}}, E_{\mathrm{C}}, n$, and $\boldsymbol{J}$ are the critical current, the electric field at the critical current, the index of the power law, and $\boldsymbol{J}_{0}+\boldsymbol{J}_{\mathrm{S}}$, respectively. The Newton-Raphson method was used to solve the non-linear equations (6), subject to condition (7).

We have developed the 2D FEM program by ourselves. An $\mathrm{AC}$ external field is given as a boundary condition. A triangular mesh is employed, and the number of nodes and elements are approximately 2.3 million and 4.7 million, respectively (including 1.6 million nodes and 3.2 million elements for the REBCO layer).

\section{B. Simulation Model}

Fig. 1 shows a schematic drawing of the simulation model, ignoring buffer layers in the tape. Table I lists the REBCO tape dimensions and the simulation conditions. The magnetic field components of $6 \mathrm{~T}$ and $3 \mathrm{~T}$ are applied in the radial and axial directions. Such a combination of the field components is evidenced, for instance, at the end turns of a high-field MRI magnet [2].

In the simulation, a sinusoidal magnetic field, $B_{\mathrm{sh}}$, with an amplitude of $30 \mathrm{mT}$ is applied to the REBCO tape by the shaking magnet (Fig. 2), after the main magnet is fully charged. The shaking field frequency is $50 \mathrm{~Hz}$, and the number of cycles is 3 . The shaking field direction relative to the tape (by the field angle) is varied from $\alpha=0$ to $360 \mathrm{deg}$. during the simulations. The assumed operating temperature and the transport current were $10 \mathrm{~K}$ and $200 \mathrm{~A}$, respectively.

Fig. 3(a) shows the current density distribution in the REBCO layer after the transport current reaches $200 \mathrm{~A}$, where the scale of $r$ axis is enlarged a thousand-fold. The current density nearby the bottom of the REBCO layer is negative due to the screening current effect. The current density distribution shown in Fig. 3(a) represents the initial condition for the shaking field effect simulation.

\section{Simulation Results}

\section{A. Shaking Magnetic Field Parallel to Tape Surface}

The simulation was done first with the shaking field applied parallel to the REBCO tape surface, $\alpha=0 \mathrm{deg}$. The current density distribution for all conductors: copper stabilizer, Hastelloy substrate, silver overlayer, and REBCO layer, at $t=$ $60 \mathrm{~ms}$ is shown in Fig. 4. As seen, current flows only in the REBCO layer. Since the current in the REBCO layer cannot be seen in Fig. 4, Fig. 3(b)-(i) show the enlarged current density distributions/maps in the REBCO layer at $t=5,10,15$, $20,30,40,50$, and $60 \mathrm{~ms}$, respectively. At the start of the

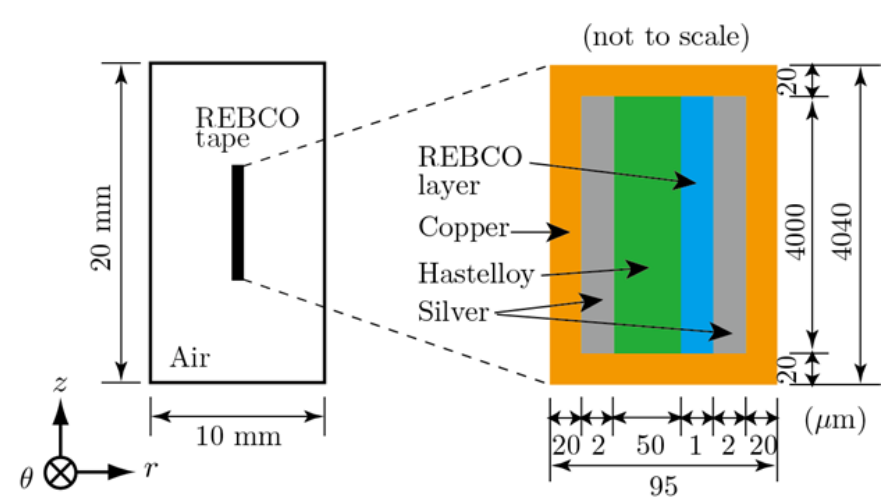

Fig. 1. Schematic drawing of the simulation model (not to scale).

TABLE I

PARAMETERS OF REBCO TAPE AND SHAKING MAGNETIC FIELd CONDITION

\begin{tabular}{ll}
\multicolumn{2}{c}{ REBCO tape } \\
REBCO tape width & $4.04 \mathrm{~mm}$ \\
REBCO tape thickness & $0.95 \mathrm{~mm}$ \\
REBCO layer width & $4.00 \mathrm{~mm}$ \\
REBCO layer thickness & $1 \mu \mathrm{m}$ \\
Copper stabilizer thickness & $20 \mu \mathrm{m}$ each side \\
Silver overlayer thickness & $2 \mu \mathrm{m}$ \\
N-value & 20 \\
\multicolumn{1}{c}{ Magnet condition } \\
Transport current & $200 \mathrm{~A}$ \\
Temperature & $10 \mathrm{~K}$ \\
\multicolumn{2}{c}{ Shaking magnetic field } \\
Magnitude of shaking field & $30 \mathrm{mT}$ (peak) \\
Shaking field frequency & $50 \mathrm{~Hz}$ \\
Number of shaking field cycle & 3 \\
Field direction & $-30-30,150-210 \mathrm{deg}$. \\
\hline
\end{tabular}

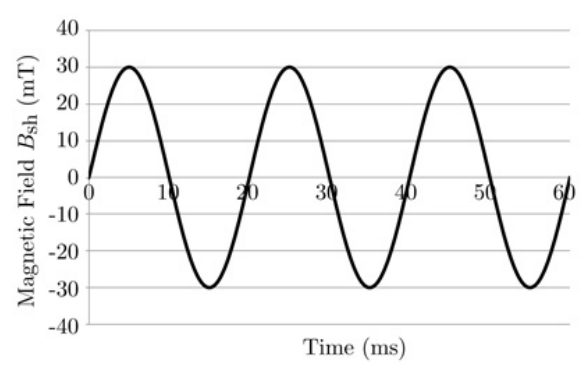

(a)

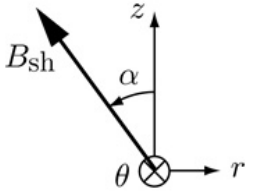

(b)
Fig. 2. External AC magnetic field of $30 \mathrm{mT}$-peak with angle $\alpha(50 \mathrm{~Hz}$, 3 cycles).

simulation, the negative current density is observed within a large area, however, the shape of the current-carrying region varies with time. Finally, at $60 \mathrm{~ms}$, large negative currents flow only near the outer surface of the REBCO, while small negative currents flow near the bottom middle of the layer. The shapes of both negative current regions are like thin needles. Such shapes weaken the influence of the screening current on the magnetic field near the magnet center, compared to the initial condition as shown in Fig. 3(a).

\section{B. Various Angled Shaking Magnetic Field}

Fig. 5 shows the current density distributions within the REBCO layer at $t=60 \mathrm{~ms}$, when applying the shaking field at the following angles: $\alpha=-30$ to 30 , and 150 to $210 \mathrm{deg}$.

As seen from Fig. 5, the negative current in the REBCO layer exists far from the coil axis in the cases of $\alpha=-30$ to 30 


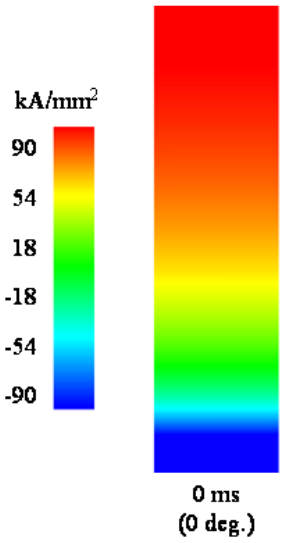

(a)

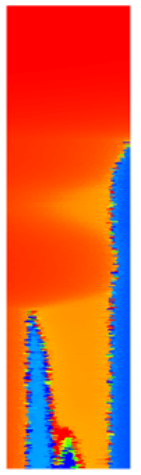

$20 \mathrm{~ms}$

(360 deg.)

(c)

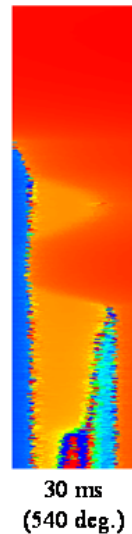

(f)

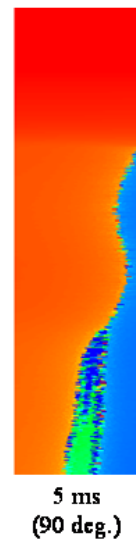

(b)

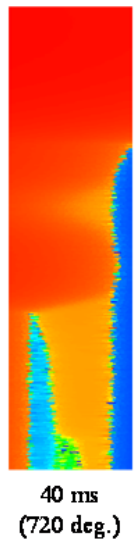

(g)

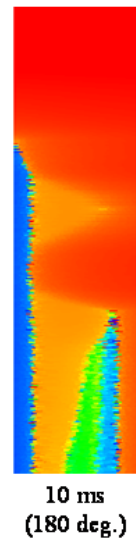

(c)

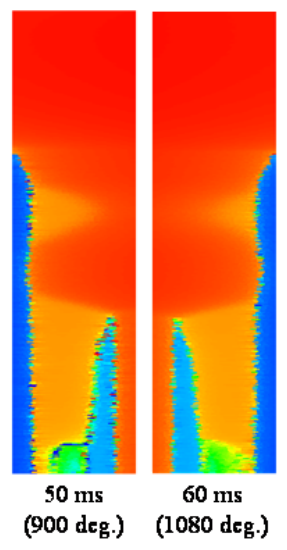

(h)

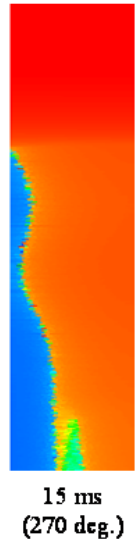

(d)
Fig. 3. Current density distribution of REBCO layer. (a) initial condition, and (b)-(i) the simulation results of $B_{\mathrm{sh}}=30 \mathrm{mT}$ and $\alpha=0 \mathrm{deg}$. The $r$ axis is enlarged 1000 times. The numbers in parentheses indicate the phase angle of the magnetic field sweep shown in Fig. 2.

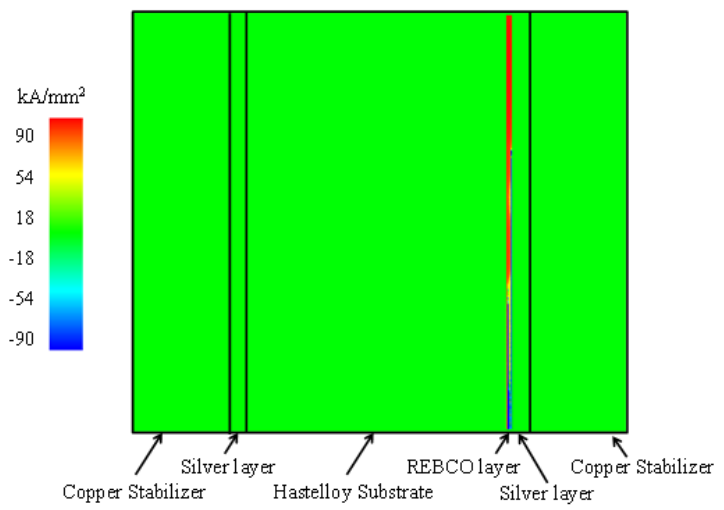

Fig. 4. Current density distribution of REBCO tape. Current does not flow in the copper stabilizer, Hastelloy substrate, or silver overlayers (not to scale).

deg. On the other hand, the negative current is closer to the coil axis when $\alpha=150$ to $210 \mathrm{deg}$. Evidently, the cases of $\alpha=$ -30 to $30 \mathrm{deg}$. are superior to $\alpha=150$ to $210 \mathrm{deg}$.

\section{Evaluation OF ShaKing Field}

It is difficult to quantify the superiority of the shaking field angle on the field homogeneity. In this work, the shaking field is evaluated from the viewpoint of the contribution from a given conductor to the center field and the area of the negative

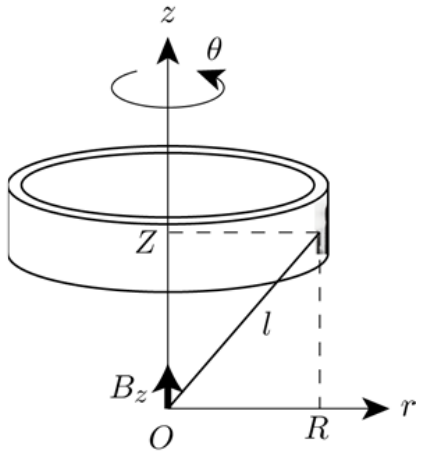

Fig. 6. Schematic drawing of a single-turn coil for evaluation of shaking field effects.

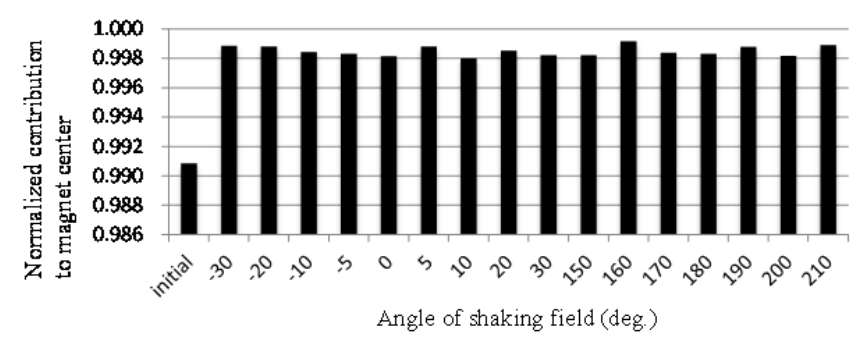

Fig. 7. Normalized contribution of a single-turn coil to the magnet center.

current inside the conductor.

\section{A. Contribution to Center Field}

The effect of the current distribution due to the shaking field on the center field is investigated first. In the calculations, the simulated REBCO tape is placed in an arbitrary position. The axial magnetic field generated by a single-turn coil is shown in Fig. 6. The superposition of magnet fields generated by the individual finite elements at the magnet center is given by

$$
B_{z}=\frac{\mu_{0}}{2} \sum_{i=1}^{n} \frac{J_{i} S_{i} r_{i}^{2}}{l_{i}^{3}}
$$

where $\mu_{0}, J_{i}, S_{i}, r_{\mathrm{i}}, l_{i}$, and $n$ are the permeability of free space, the current density, the area, the radius, and the distance from the origin for $i$ th element, and the total number of finite elements, respectively.

Fig. 7 shows the field contribution at the magnet center for every shaking angle, where the values are normalized to the contribution for an ideal, homogeneous current distribution. The simulated REBCO tape is placed at $R=50 \mathrm{~cm}$ and $Z=70$ cm. In Fig. 7, the "initial" value means the current distribution just after energizing the single-turn coil. The magnetic field of the initial condition is small, and it approaches 1 after applying a shaking field at any angle to the tape.

Next, Fig. 8 shows the ratio of the field contributions from the negative and positive current $B_{z^{-}} / B_{z^{+}}$, where $B_{z^{-}}, B_{z^{+}}$are center field components generated by the negative and positive current, respectively. Since it takes a very long time to decay, it is desirable that the ratio $B_{z^{-}} / B_{z^{+}}$is close to zero to minimize the screening current effect.

From Fig. 8, the initial condition is the worst among them, i.e., the negative current density appears over a large region close to the magnet center inside the REBCO layer. It would 


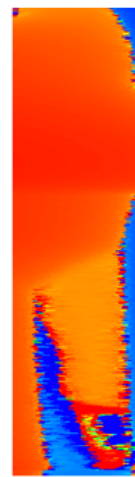

$-30 \mathrm{deg}$.

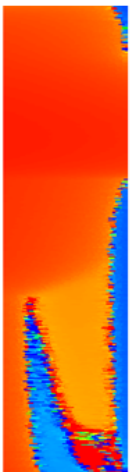

-20 deg.

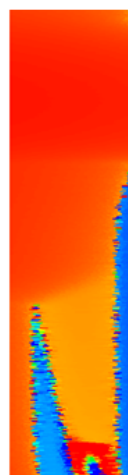

$-10 \mathrm{deg}$.

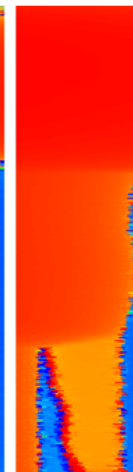

-5 deg.

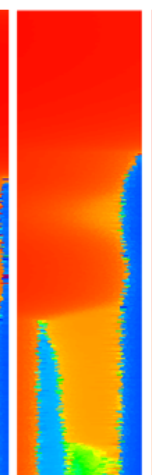

0 deg.

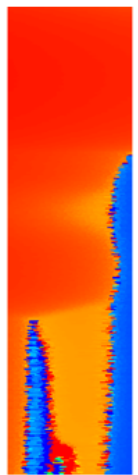

5 deg.

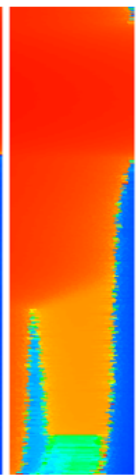

$10 \mathrm{deg}$.

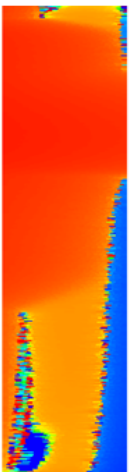

$20 \mathrm{deg}$.

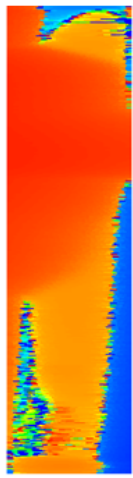

$30 \mathrm{deg}$.

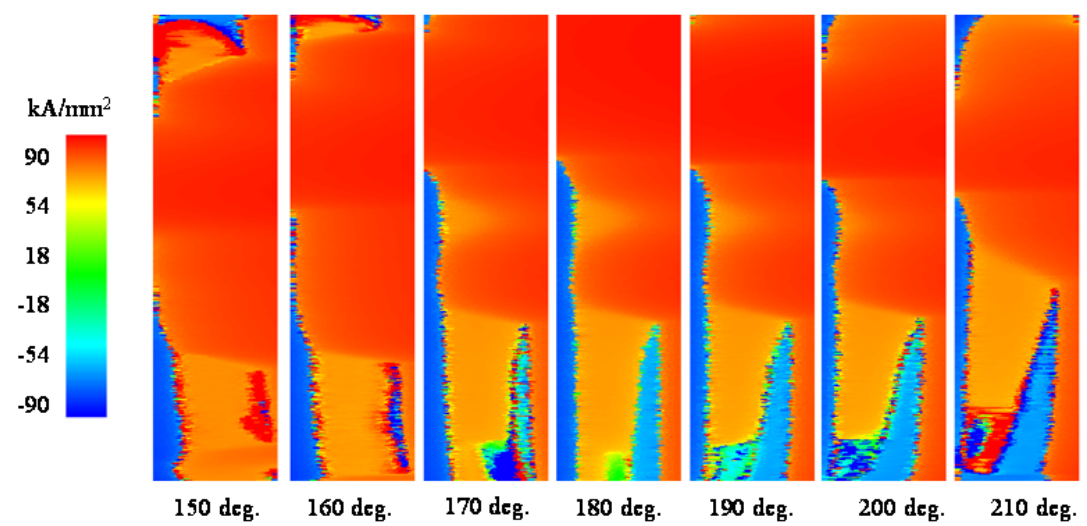

Fig. 5. Current density distribution in REBCO layer at different field angles $\alpha=-30-30$ and 150-210 deg. at $t=60 \mathrm{~ms}$. The $r$ axis is enlarged 1000 times.

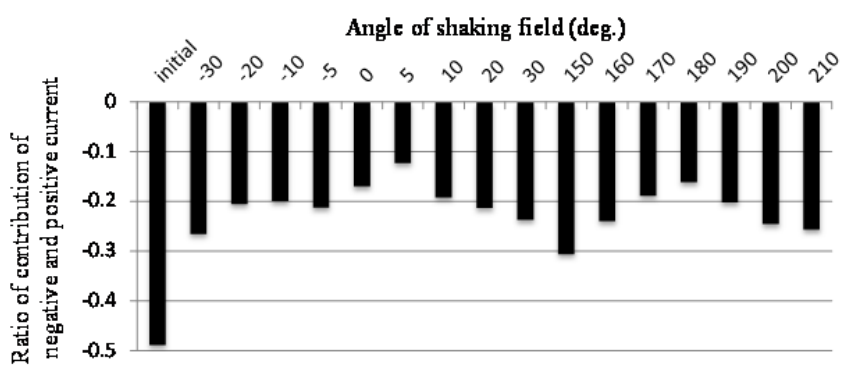

Fig. 8. Ratio of negative and positive contributions to the magnet center.

deteriorate the field homogeneity if the REBCO layer on consideration was in a real magnet winding. From Fig. 8, the angle of $5 \mathrm{deg}$. minimizes the negative current contribution.

\section{B. Area of Negative Current}

Fig. 9 shows the area of the high negative current density (< $-60 \mathrm{kA} / \mathrm{mm}^{2}$ ) inside the REBCO layer. The area is obviously small at $0-10$ and $180 \mathrm{deg}$.

Considering the above results, the best shaking field angle is between 0 and $10 \mathrm{deg}$.

\section{CONCLUSION}

Simulation results of the current distribution inside a REBCO tape in the shaking field applied at different angles are presented. From the obtained simulation results, the center magnetic field generated by a aingle-turn coil with the current distributions is also investigated. The shaking field applied at almost any angle effectively reduces the negative effect of the

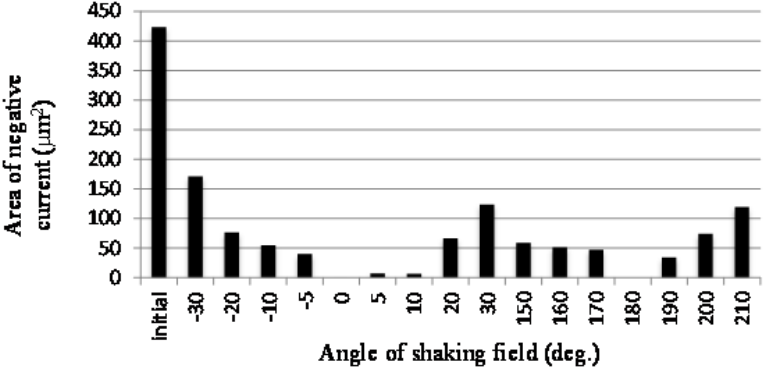

Fig. 9. Area of negative current carrying region.

screening current on the magnet central field. The best shaking field angle value is -30 deg., albeit only from the standpoint of the screening current effect reduction.

Since the negative currents decay for a long time, a minimal amount of negative current is desirable. From the results, we concluded that an $\mathrm{AC}$ magnetic field with angle between 0 and $10 \mathrm{deg}$. produces the greatest shaking effect.

In this paper, only one REBCO tape is considered in the shaking field simulation. However, since there are many turns of a REBCO tape in a magnet, the electromagnetic interaction between the turns should be included appropriately. Also, the authors plan to investigate the effect of the shaking field strength on the screening current reduction.

\section{REFERENCES}

[1] J. Bascuñán, S. Hahn, Y. Kim, and Y. Iwasa, "A New High-Temperature Superconducting (HTS) 700-MHz Insert Magnet for a $1.3-\mathrm{GHz}$ 
LTS/HTS NMR Magnet," IEEE Trans Appl. Supercond., vol. 23, no. 3, Jun. 2013, Art. ID. 4400304.

[2] T. Tosaka, H. Miyazaki, S. Iwai, Y. Otani, M. Takahashi, K. Tasaki, S. Nomura, T. Kurusu, H. Ueda, S. Noguchi, A. Ishiyama, S. Urayama, and H. Fukuyama, "R\&D Project on HTS Magnets for Ultrahigh-Field MRI Systems," IEEE Trans. Appl. Supercond., vol. 26, no. 4, Jun. 2016, Art. ID. 4402505.

[3] S. Hahn, D. K. Park, J. Bascunan, and Y. Iwasa, "HTS Pancake Coils Without Turn-to-Turn Insulation," IEEE Trans. Appl. Supercond., vol. 21, no. 3, pp. 1592-1595, Jun. 2011.

[4] S. Hahn, D. K. Park, J. Voccio, J. Bascunan, and Y. Iwasa, "NoInsulation (NI) HTS Inserts for > $1 \mathrm{GHz}$ LTS/HTS NMR Magnets," IEEE Trans. Appl. Supercond., vol. 22, no. 3, Jun. 2012, Art. ID. 4302405.

[5] Y. Kim, Y. H. Choi, D. G. Yang, H. Shin, M. C. Ahn, H. Lee, "Study for Reducing the Screening Current-Induced Field in a $10-\mathrm{MHz}$ NoInsulation Magnet Using Current Sweep Reversal Method," IEEE Trans. Appl. Supercond., vol. 25, no. 3, Jun. 2015, Art. ID. 4601005.

[6] K. Kajikawa and Y. Okabe, "Reduction of Screening-Current-Induced Fields in an HTS Tape Winding Using Toroidal Arrangement of Shaking Coil," IEEE Trans. Appl. Supercond., vol. 26, no. 4, Jun. 2016, Art. ID. 4400504.

[7] M. C. Ahn, T. Yagai, S. Hahn, R. Ando, J. Bascunan, and Y. Iwasa, "Spatial and Temporal Variations of a Screening Current Induced Magnetic Field in a Double-Pancake HTS Insert of an LTS/HTS NMR Magnet," IEEE Trans. Appl. Supercond., vol. 19, no. 3, pp. 2269-2272, Jun. 2009.

[8] H. Ueda, Y. Imaichi, T. Wang, A. Ishiyama, S. Noguchi, S. Iwai, H. Miyazaki, T. Tosaka, S. Nomura, T. Kurusu, S. Urayama, and H. Fukuyama, "Numerical Simulation on Magnetic Field Generated by Screening Current in 10-T-Class REBCO Coil," IEEE Trans. Appl. Supercond., vol. 26, no. 4, Jun. 2016, Art. ID. 4701205.

[9] K. Kajikawa, G. V. Gettliffe, Y. Chu, D. Miyagi, T. P. Lécrevisse, S. Hahn, J. Bascuñán, and Y. Iwasa, "Designs and Tests of Shaking Coils to Reduce Screening Currents Induced in HTS Insert Coils for NMR Magnet," IEEE Trans. Appl. Supercond., vol. 25, no. 3, Jun. 2015, Art. ID. 4300305 .

[10] J. Xia, H. Bai, J. Lu, A. Gavrilin, Y. Zhou, and H. Weijers, "Electromagnetic modeling of REBCO high field coils by the Hformulation," Supercond. Sci. Technol., vol. 28, no. 12, Oct. 2015 Art. ID. 125004.

[11] N. Amemiya, Y. Sogabe, M. Sakashita, Y. Iwata, K. Noda, T. Ogitsu, Y. Ishii, and T. Kurusu, "Magnetisation and field quality of a cosine-theta dipole magnet wound with coated conductors for rotating gantry for hadron cancer therapy," Supercond. Sci. Technol., vol. 29, no. 2, Dec. 2015, Art. ID. 024006.

[12] L. Quéval, V. Zermeño, and F. Grilli, "Numerical models for ac loss calculation in large-scale applications of HTS coated conductors," Supercond. Sci. Technol., vol. 29, no. 2, Jan. 2016, Art. ID. 024007.

[13] E. Pardo, "Modeling of screening currents in coated conductor magnets containing up to 40000 turns," Supercond. Sci. Technol., vol. 29, no. 8, Jun. 2016, Art. ID. 085004.

[14] V. Lahtinen, E. Pardo, J. Šouc, M. Solovyov, and A. Stenvall, "Ripple field losses in direct current biased superconductors: Simulations and comparison measurements," J. Appl. Phys., vol. 115, 2014, Art. ID. 113907.

[15] Z. Xu and F. Grilli, "Modelling ac ripple currents in HTS coated conductors," Supercond. Sci. Technol., vol. 28, no. 10, Aug. 2015, Art. ID. 104002.

[16] T. Nakata, N. Takahashi, and K. Fujiwara, "Physical meaning of $\operatorname{grad} \phi$ in eddy current analysis using magnetic vector potentials," IEEE Trans. Magn., vol. 24, no. 1, pp. 178-181, Jan. 1988. 